\title{
Women's perspectives on antenatal breast expression: a cross-sectional survey
}

Frankie J. Fair ${ }^{1}$, Helen Watson ${ }^{1}$, Rachel Gardner ${ }^{2}$ and Hora Soltani ${ }^{{ }^{*}}$

\begin{abstract}
Background: The practice of antenatal breast expression (ABE) has been proposed as a strategy to promote successful breastfeeding. Although there has been some focus on the evaluation of the effects of $A B E$ in promotion of breastfeeding, little or no evidence exists on women's experiences of $A B E$ or opinions on $A B E$, particularly amongst overweight or obese women.

Methods: This study aimed to explore women's knowledge, practices and opinions of ABE, and any differences within the overweight and obese subgroups. A cross-sectional survey was undertaken using an online questionnaire distributed by a maternity user group representative via social media. Quantitative data were analysed using Chi-square and Fisher's exact tests in SPSS. Simple thematic analysis was used for the qualitative data.

Results: A total of 688 responses were analysed; the sample represented a group of breastfeeding mothers, of whom $64.5 \%$ had heard of $A B E, 8.2 \%$ had been advised to do $A B E$, and $14.2 \%$ had undertaken ABE. Of the women who had been advised to do ABE, 67.9\% had complied. Most participants (58.6\%) were unsure if ABE was a good idea; however $80.9 \%$ would consider doing $A B E$ if it was found to be helpful to prepare for breastfeeding. Women in the overweight or obese subgroups were significantly more likely to have heard of $A B E(p<0.001)$, and positive opinion of $A B E$ also increased with higher BMI groups. The qualitative data demonstrated participants felt ABE may be beneficial when mother or baby have medical problems, and in preparation for breastfeeding, but highlighted their concerns that it may interfere with nature and be harmful, and that they wanted more information and knowledge about ABE.
\end{abstract}

Conclusions: Amongst women who have breastfed, many have heard of $A B E$, compliance with advice to undertake $A B E$ is relatively high, and $A B E$ is considered an acceptable practice. Further investigation into the benefits and safety of $A B E$ is warranted, to address the needs of childbearing women for evidence-based information about this practice. If the evidence base is established, overweight and obese pregnant women could be an important target group for this intervention.

Keywords: Antenatal breast expression, Maternal obesity, Breastfeeding, Survey, Opinions, Compliance

\section{Plain English summary}

It has been proposed that the manual expression of breastmilk whilst a woman is still pregnant (ABE) may promote breastfeeding. A few studies have evaluated the effects of $\mathrm{ABE}$ on promotion of breastfeeding but to our knowledge no study has focused on exploring women's experiences and opinions about this practice on a large scale.

This study aimed to investigate women's experiences of and opinions on this practice by undertaking a questionnaire based survey. This was distributed online and

\footnotetext{
* Correspondence: h.soltani@shu.ac.uk

${ }^{1}$ Faculty of Health and Wellbeing, Sheffield Hallam University, Collegiate

Crescent, Sheffield, UK

Full list of author information is available at the end of the article
}

a total of 688 responses were analysed. The respondents were predominately a group of breastfeeding mothers, of whom $64.5 \%$ had heard of $\mathrm{ABE}, 8.2 \%$ had been advised to do $\mathrm{ABE}$, and $14.2 \%$ had undertaken $\mathrm{ABE}$. Of the women who had been advised to do $\mathrm{ABE}, 67.9 \%$ had followed this advice. Most participants (58.6\%) were unsure if $A B E$ was a good idea; however $80.9 \%$ would consider doing $\mathrm{ABE}$ if it was found to help prepare for breastfeeding. Overweight or obese women were more likely to have heard of $\mathrm{ABE}$, and were equally as positive about undertaking it if it was found to help prepare for breastfeeding. Women felt that ABE may be beneficial when mother or baby have medical problems, and in 
preparation for breastfeeding, but had concerns that it may interfere with nature and be harmful, and said that they wanted more information about $\mathrm{ABE}$. If further research finds that $A B E$ is safe and effective, it could be developed as an intervention to promote breastfeeding, particularly for overweight and obese pregnant women.

\section{Background}

The World Health Organization recommends that infants are exclusively breastfed until 6 months of age with continued breastfeeding thereafter alongside appropriate complementary foods [1]. The health benefits of breastfeeding for both the mother and the infant are well documented [2-4]. However, the practice of breastfeeding varies extensively and identifying appropriate strategies to promote breastfeeding amongst all women are required.

\section{Factors influencing breastfeeding}

The United Kingdom (UK) Infant feeding Survey has demonstrated that the prevalence of breastfeeding is higher amongst mothers from managerial and professional occupations, those who left education aged over 18, mothers aged 30 and over, mothers from ethnic minority groups and mothers living in the least deprived areas [5].

A lower prevalence of breastfeeding and poorer breastfeeding outcomes among women who are overweight or obese is well supported by epidemiological studies [613]. Maternal obesity is associated with up to $13 \%$ lower breastfeeding initiation rates, and shorter duration of any breastfeeding and exclusive breastfeeding when compared to women of normal weight $[13,14]$. This is of particular concern given the rising rate of overweight and obesity across the globe [15], with rates in women aged 20 years or over within the UK in 2013 standing at $57.2 \%$ with a body mass index (BMI) $\geq 25 \mathrm{~kg} / \mathrm{m}^{2}$ and 25 . $4 \%$ with a $B M I \geq 30 \mathrm{~kg} / \mathrm{m}^{2}$ [16].

Although psychosocial factors are significantly associated with the lower incidence of breastfeeding among women with a BMI over $25 \mathrm{~kg} / \mathrm{m}^{2}$, anatomical and physiological alterations may also play a role. Among these is that women who are overweight or obese may have mammary hypoplasia or insufficient glandular tissue as obesity in childhood negatively affects the development of breast glandular tissue [13]. Many of the characteristics experienced by women who are overweight or obese are consistent with this, including reporting stopping breastfeeding due to perceived insufficient supply [17] and being more likely to try to express in the first 2 months postpartum but less likely to have successfully expressed than women with a normal BMI [18]. A high pre-pregnancy BMI is also a predictor of delayed onset lactogenesis II [19], which is the production of copious milk triggered by progesterone withdrawal after the removal of the placenta [13, 20]. This most critical stage of the lactation cycle [21] is more likely to be delayed (occurring more than $72 \mathrm{~h}$ after birth) amongst women with a high BMI than women of normal weight [22]. Various underlying physiological reasons for the increased likelihood of delayed lactogenesis II amongst women with obesity are proposed; the impact of increased oedema [13], increased likelihood of medical problems including gestational diabetes, prolonged labour, caesarean section or preterm birth $[6,23]$, the role of leptin released from adipose tissue which inhibits oxytocin and milk ejection [13], reduced prolactin response to infant suckling [24], and the impact of insulin imbalance [13].

\section{Antenatal breast expression}

The practice of antenatal breast expression (ABE) has been proposed as a strategy to prevent delayed lactogenesis II in both the academic and consumer literature [25, 26], and as a strategy to overcome the effects of delayed lactogenesis II by ensuring women have a store of expressed milk to prevent the use of formula milk, particularly if the mother has pre-existing or gestational diabetes [27-29]. ABE is widely recommended in UK maternity units [30-43]. A recent survey demonstrated that out of the 56 responding maternity units across 9 geographical regions in the UK, $73 \%$ offered $\mathrm{ABE}$ to diabetic women, $25 \%$ offered $\mathrm{ABE}$ to women who had risk factors for neonatal hypoglycaemia, and 19\% offered $A B E$ to all women [44]. Furthermore, the practice of $\mathrm{ABE}$ is promoted by some lactation support websites $[29,45]$.

$\mathrm{ABE}$ involves expressing colostrum from the breast in the antenatal period, however there is little consensus on timing of onset, frequency, duration and method of expression. Recommendations vary within the academic and consumer literature and local UK guidelines on when to commence ABE. A majority of UK maternity units recommend commencing $\mathrm{ABE}$ from 36 to 37 weeks (98\%) with only $2 \%$ recommending commencing $\mathrm{ABE}$ at 35,38 or 39 weeks gestation [44], however consumer literature recommends commencing $\mathrm{ABE}$ from 32 to 34 weeks of pregnancy [29]. Similarly recommendations regarding how to express $\mathrm{ABE}$ vary, including frequency ranging from once a day [35], building up to 4 times a day [32, 34, 39] a minimum of 4 times a day [43] or as often as the woman wants $[36,40]$ and duration varying from $5 \mathrm{~min}$ [35] up to $20 \mathrm{~min}$ at a time [32, 38, 39].

Evidence of the effectiveness or underlying mechanism of action of $\mathrm{ABE}$ are still not clear, although several studies including a recent large randomised controlled trial have focused on evaluating the safety and efficacy of $\mathrm{ABE}$ among women with diabetes [27, 46-48]. Initial concerns raised in a retrospective cohort study about 
the safety of $\mathrm{ABE}$ in regards to influencing the timing of onset of labour if $\mathrm{ABE}$ was commenced prior to 37 weeks' gestation [49] have not been supported by a large randomised controlled trial of women at low risk of complications with diabetes in pregnancy [48]. This trial found no difference in gestational at birth between those randomised to ABE from 36 weeks' gestation and women randomised to standard care [48].

Given that $\mathrm{ABE}$ is a widely recommended practice in maternity units and on lactation support websites and that limited evaluation of the acceptability of $\mathrm{ABE}$ to prepare for breastfeeding has been undertaken, a wide scoping of acceptability and women's views on this practice merits a focused exploration.

This study was therefore designed to assess the general knowledge of $\mathrm{ABE}$ among mothers, their practices surrounding $\mathrm{ABE}$ and the acceptability of $\mathrm{ABE}$ to them should it be found to be an effective preparation for breastfeeding. It was also aimed to explore any differences in knowledge and acceptability within the overweight and obese subgroup of mothers.

\section{Methods}

A cross-sectional survey using a questionnaire was developed in consultation with maternity user group representatives; individuals representing the opinions of mothers and fathers currently expecting a baby or with a child under 1 year old. The survey questionnaire was generated using the online, cloud-based software, Survey Monkey. Applying a convenience sampling strategy, the questionnaire was distributed from December 2015 to January 2016 through a maternity service user and parenting Facebook group, which was moderated by the maternity user group representative member of the research team. This Facebook group aimed to allow parents to share stories and gain peer support, it was not focussed on method of infant feeding.

The questionnaire consisted of a mixture of question types, including free text questions and fixed response options. Demographic data was collected, including place of residence, ethnicity, age, number of pregnancies, and occupation of participants. In order to calculate BMI, the survey included a question about the participants' height and weight at the time of the survey, in either metric or imperial units.

Survey questions covered the following topics; whether participants had ever breastfed and for how long, whether they had heard of the practice of $\mathrm{ABE}$, had been advised to do $\mathrm{ABE}$ and had undertaken $\mathrm{ABE}$, and their opinion on whether $\mathrm{ABE}$ was a good idea and if they would consider doing $\mathrm{ABE}$ if it was found to be beneficial to breastfeeding.

Ethical approval was obtained from Sheffield Hallam University Research Ethics Committee, study ID: 2015-
16/ HWB-HSC-14. Consent was assumed inherent for the participants who completed the questionnaire voluntarily.

\section{Data analysis}

Logical checks and data cleaning were carried out and inconsistencies double checked for clarification. All survey data were double-entered and cleaned using SPSS 21.0. Descriptive statistics including proportions, ranges, means, standard deviation (SD), median and interquartile ranges (IQR) as appropriate were calculated for the demographic data and for closed answer questions. Categorical data were analysed using Chi-square test or Fisher's exact test where the assumptions for Chi-square test were not satisfied, such as expected count $<5$ in over $20 \%$ of cells. A $p$ value $<0.05$ was regarded as indicating statistical significance.

BMI values were calculated from the reported height and weight measurements and grouped into 3 categories; BMI less than $25 \mathrm{~kg} / \mathrm{m}^{2}$, overweight (BMI of 25-29. $9 \mathrm{~kg} / \mathrm{m}^{2}$ ) and obese (BMI of $30 \mathrm{~kg} / \mathrm{m}^{2}$ or more) [50]. Occupations of the participants were coded using the 3 category National Statistics Socio-economic Classification (NS-SEC) system [51].

Simple thematic analysis was used for the open ended questions by coding the data after familiarisation, and deriving categories and themes inductively.

\section{Results \\ Respondent characteristics}

There were 797 completed surveys. Nineteen responses were removed; eighteen repeat responses and one with implausible demographic responses. A total of 778 responses were coded and taken forward for analysis. The participants completing the survey ranged in age from 19 to 62 (mean 33.3, SD 5.7). Most of the respondents (94.8\%) were living in the UK, 2.9\% were in North America and a small proportion were living in other European countries or the continents of Asia, Australia and Oceania or South America (2.1\%). Further analysis was limited to the 688 participants who were living in the UK, of childbearing age (16-44) and who had given birth to at least one child. Characteristics of the participants are presented in Table 1.

Most of the participants (95.5\%) identified their ethnicity as White, $2.3 \%$ as Mixed ethnicity, $1.0 \%$ as Black, 1 . $2 \%$ as Asian. The wide geographical distribution of UK respondents can be seen in Additional file 1. The BMI of the respondents ranged from $16.7 \mathrm{~kg} / \mathrm{m}^{2}$ to $66.6 \mathrm{~kg} / \mathrm{m}^{2}$ (mean $26.8 \mathrm{~kg} / \mathrm{m}^{2}$, SD 6.0 ), $43.2 \%$ had a BMI of less than $25 \mathrm{~kg} / \mathrm{m}^{2}, 32.1 \%$ were categorised as overweight and 24 . $7 \%$ were in the obese category.

The largest occupational group category amongst the participants was higher managerial, administrative and professional occupations (52.3\%), although $21.9 \%$ of 
Table 1 Characteristics of UK respondents compared to UK national values

\begin{tabular}{|c|c|c|}
\hline & UK participants at time of survey $(n=688)$ & National values $\%$ \\
\hline & \multicolumn{2}{|l|}{$n(\%)$} \\
\hline Age & $(n=688)$ & Women giving birth in England \\
\hline Under 20 & $2(0.3 \%)$ & $4.6^{\mathrm{a}}$ \\
\hline $20-24$ & $27(3.9 \%)$ & $18.2^{\mathrm{a}}$ \\
\hline $25-29$ & $140(20.4 \%)$ & $28.1^{\mathrm{a}}$ \\
\hline $30-34$ & $266(38.7 \%)$ & $29.7^{\mathrm{a}}$ \\
\hline $35-39$ & $197(28.6 \%)$ & $15.5^{\mathrm{a}}$ \\
\hline $40+$ & $56(8.1 \%)$ & $3.9^{\mathrm{a}}$ \\
\hline Ethnicity & $(n=683)$ & \\
\hline White & $652(95.5 \%)$ & $86.0^{\mathrm{b}}$ \\
\hline Black & $7(1.0 \%)$ & $3.3^{b}$ \\
\hline Asian & $8(1.2 \%)$ & $7.5^{\mathrm{b}}$ \\
\hline Mixed & $16(2.3 \%)$ & $2.2^{\mathrm{b}}$ \\
\hline BMl & $(n=663)$ & All women in England \\
\hline$<25$ & $286(43.2 \%)$ & $42.8^{c}$ \\
\hline Overweight & $213(32.1 \%)$ & $33.4^{c}$ \\
\hline Obese & $164(24.7 \%)$ & $23.8^{c}$ \\
\hline Occupation & $(n=683)$ & Female UK residents aged $16-74$ \\
\hline Higher managerial, administrative and professional occupations & $357(52.3)$ & $29.0^{d}$ \\
\hline Intermediate occupations & $117(17.1)$ & $24.0^{d}$ \\
\hline Routine and manual occupations & $59(8.6)$ & $31.0^{\mathrm{d}}$ \\
\hline Long-term unemployed or never worked & $1(0.1)$ & $6.0^{d}$ \\
\hline Not classified & $149(21.9)$ & - \\
\hline Number of children birthed & $(n=681)$ & \\
\hline 1 & $322(46.8)$ & \\
\hline 2 & $259(37.6)$ & \\
\hline 3 or more & $107(15.6)$ & \\
\hline
\end{tabular}

${ }^{\mathrm{a} A g e}$ at delivery $[53] ;{ }^{\mathrm{b}}[54] ;{ }^{\mathrm{c}}[55] ;{ }^{\mathrm{d}}[56]$

participants' occupations fell into the NS-SEC unclassified category. A total of $46.8 \%$ of the participants had given birth to one child, $37.6 \%$ had given birth to two children and $15.6 \%$ three or more children.

\section{Breastfeeding}

A total of 677 participants had breastfed (98.4\%), with 337 of these women $(50.0 \%)$ mentioning that they were currently breastfeeding at the time of completing the survey. Only 650 of the participants responded to the question about longest length of time breastfeeding a child, which ranged from 0.05 months to 72 months (mean 17.3, median 15.0 (IQR $=7.7-24.0$ )); 95.2\% reported that they were still breastfeeding at 8 weeks, 84 . $0 \%$ were breastfeeding at 6 months, $64.8 \%$ were breastfeeding at 12 months and $58.8 \%$ breastfed beyond 12 months.
Antenatal breast expression - awareness and experience A total of 442 (64.5\%) of the respondents had heard of $\mathrm{ABE}, 56(8.2 \%)$ reported that they had been advised to express breastmilk during pregnancy, and 97 (14.2\%) reported that they had undertaken breast expression during pregnancy (See Fig. 1).

Of the 97 participants who had expressed breastmilk during pregnancy, 38 had been advised to (39.2\%), 57 (58.8\%) had not been advised to and 2 (2.1\%) could not remember if they had been advised to. Of the 56 women who reported that they had been advised to express breastmilk during pregnancy, 38 (67.9\%) actually expressed, compared to $9.3 \%$ of women who had not been advised to express (Fig. 2).

Women who undertook $\mathrm{ABE}$ commenced expressing between 0 and 41 weeks of pregnancy, with a median of 36 weeks: 2 (2.2\%) reported commencing $\mathrm{ABE}$ at 0 weeks of pregnancy, 5 (5.4\%) between week 12 and 28, 43 (46. 


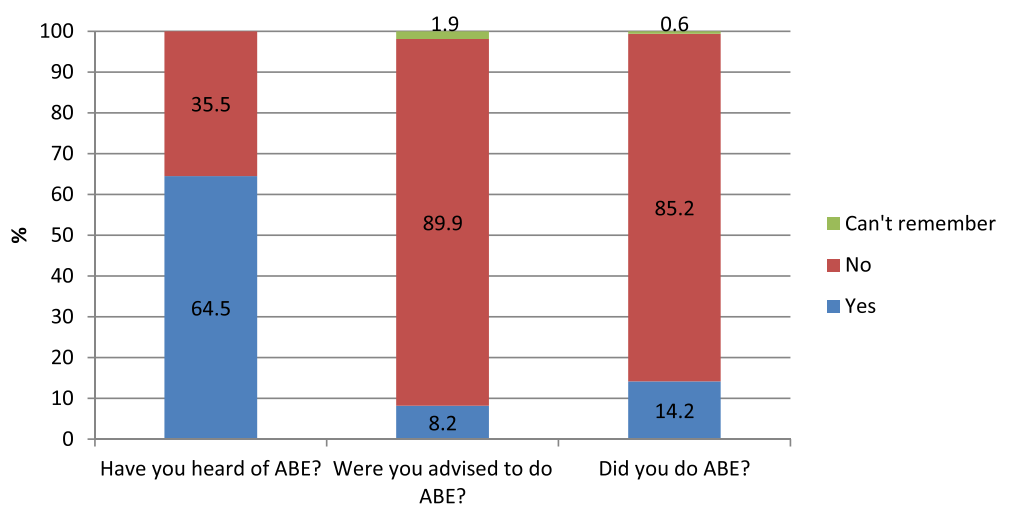

Fig. 1 Whether participants had heard of, were advised to do and if they did Antenatal Breast Expression $(n=688)$

7\%) between weeks 28 and 37, and 44 (45.7\%) from 37 weeks onwards. Women who had practiced ABE reported giving birth at a mean of 39.7 weeks gestation in their last pregnancy, which was similar to the 39.3 weeks mean length of gestation reported by women who did not undertake $\mathrm{ABE}$.

\section{Opinions on antenatal breast expression}

A majority of respondents, 398 (58.6\%), were not sure if $\mathrm{ABE}$ was a good idea, with 233 (34.3\%) of the respondents stating that they thought ABE was a good idea and $48(7.1 \%)$ thinking ABE was not a good idea (See Table 2). Previous practice of ABE was statistically significantly associated with opinion of $\mathrm{ABE}(p<0.001)$; the proportion of women who thought $\mathrm{ABE}$ was a good idea was highest in those who had undertaken $\mathrm{ABE}$ previously (78.4\%), although $26.8 \%$ of those who had not previously undertaken $\mathrm{ABE}$ still thought $\mathrm{ABE}$ was a good idea.
A total of 547 (80.9\%) of participants stated that they would consider doing $\mathrm{ABE}$ if it was found to help prepare for breastfeeding (See Table 2). Previous practice of $\mathrm{ABE}$ was significantly associated with whether participants would consider doing $\mathrm{ABE}$ in the future $(p<0.001)$, with only one participant $(1.0 \%)$ who had previously done $\mathrm{ABE}$ reporting she would not consider doing $A B E$ again if it was found to be helpful to prepare for breastfeeding.

\section{Overweight and obese subgroups}

In this sample, the proportion of women who had heard of $\mathrm{ABE}$ increased with increasing BMI group; $56.7 \%$ of women with a BMI of less than $25 \mathrm{~kg} / \mathrm{m}^{2}$ had heard of $\mathrm{ABE}$ compared to $63.2 \%$ of participants with a BMI within the overweight subgroup $78.7 \%$ within the obese subgroup (See Fig. 3). This association showed statistical significance $(p<0.001)$.

The proportion of women who thought $\mathrm{ABE}$ was a good idea also increased with increasing BMI group (See

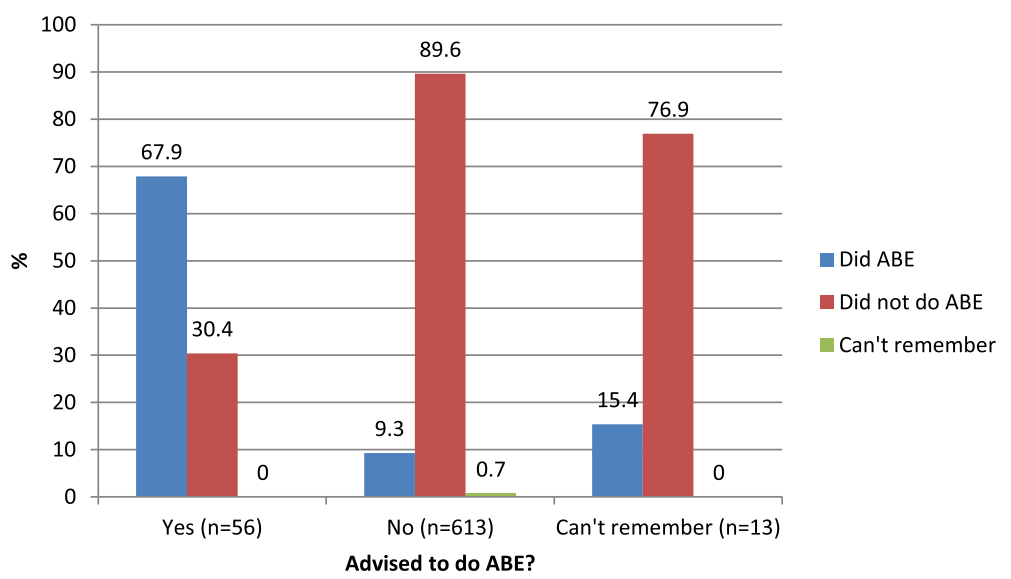

Fig. 2 Whether participants who were advised to do ABE undertook ABE $(n=682)$ 
Table 2 Participants' opinions on ABE

\begin{tabular}{|c|c|c|c|c|c|c|c|c|c|c|}
\hline & & \multirow[t]{2}{*}{ All participants } & \multicolumn{4}{|c|}{ Previously undertaken ABE? } & \multicolumn{4}{|l|}{ BMl } \\
\hline & & & Yes & No & $\begin{array}{l}\text { Can't } \\
\text { remember }\end{array}$ & $P$ value & $\begin{array}{l}\text { Under } \\
25 \mathrm{~kg} / \mathrm{m}^{2}\end{array}$ & Overweight & Obese & $P$ value \\
\hline & & $n(\%)$ & $n(\%)$ & $n(\%)$ & $n(\%)$ & & $n(\%)$ & $n(\%)$ & $n(\%)$ & \\
\hline \multirow[t]{3}{*}{ Is ABE a good idea? } & Yes & $233(34.3)$ & $76(78.4)$ & $153(26.8)$ & $1(25.0)$ & $+p<0.001$ & $85(30.2)$ & $67(31.8)$ & $76(46.6)$ & 0.007 \\
\hline & No & $48(7.1)$ & $1(1.0)$ & $47(8.2)$ & $0(0.0)$ & & $19(6.8)$ & $15(7.1)$ & $11(6.8)$ & \\
\hline & Not sure & $398(58.6)$ & $20(20.6)$ & $372(65.0)$ & $3(75.0)$ & & $177(63.0)$ & $129(61.1)$ & $76(46.6)$ & \\
\hline \multirow{3}{*}{$\begin{array}{l}\text { Would you consider doing } \\
\text { ABE if it was found to help } \\
\text { prepare for breastfeeding? }\end{array}$} & Yes & $547(80.9)$ & $94(96.9)$ & $445(78.1)$ & $4(100)$ & $+p<0.001$ & $220(79.4)$ & $175(82.6)$ & $134(82.2)$ & 0.280 \\
\hline & No & $43(6.4)$ & $1(1.0)$ & $42(7.4)$ & $0(0.0)$ & & $15(5.4)$ & $13(6.1)$ & $14(8.6)$ & \\
\hline & Not sure & $86(12.7)$ & $2(2.1)$ & $83(14.5)$ & $0(0.0)$ & & $42(15.2)$ & $24(11.3)$ & $15(9.2)$ & \\
\hline
\end{tabular}

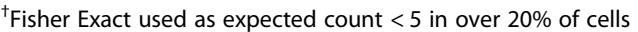

Fig. 3); $46.6 \%$ of obese participants thought it was a good idea, compared with $31.8 \%$ of those who were overweight and $30.2 \%$ of those with a BMI of less than $25 \mathrm{~kg} / \mathrm{m}^{2}$, and this association was statistically significant $(p=0.007)$. However, there was no significant association between BMI group and whether participants would consider doing $\mathrm{ABE}$ in the future $(p=0.280)$.

\section{Qualitative data - Women's opinions on antenatal breast expression}

Several themes emerged from the qualitative data (See Table 3). Amongst participants who felt ABE was a good idea these were; beneficial when mother or baby have medical problems, and preparation for breastfeeding. The themes that emerged amongst participants who thought that $\mathrm{ABE}$ was not a good idea were; interfering with nature and harmful. For those who were unsure if $\mathrm{ABE}$ was a good idea the main theme was lack of knowledge.

\section{Positive perceptions}

Participants who thought that $\mathrm{ABE}$ was a good idea felt it would be beneficial where mother or baby have medical problems including gestational or pre-existing diabetes, previous breast surgery, complications after birth, prematurity, low blood sugars, admission to neonatal unit or difficulties feeding;

"If there are any complications during labour which meant that you were unable to feed initially (I.e. PPH [postpartum haemorrhage], or surgery was required taking you away from baby) baby could be spoon or cup feed colostrum. Equally if baby is struggling with blood sugars, jaundice, weight loss."

\section{"I have type 1 diabetes, antenatal expression} enabled me to collect colostrum and give it to my babies at birth preventing them from having low blood sugar."

They also referred to $\mathrm{ABE}$ as positive preparation for successful breastfeeding, including the opportunity to become more confident with the expressing technique that they could use again after the birth, establishing a supply of colostrum, encouraging the milk supply and avoiding the use of formula milk;

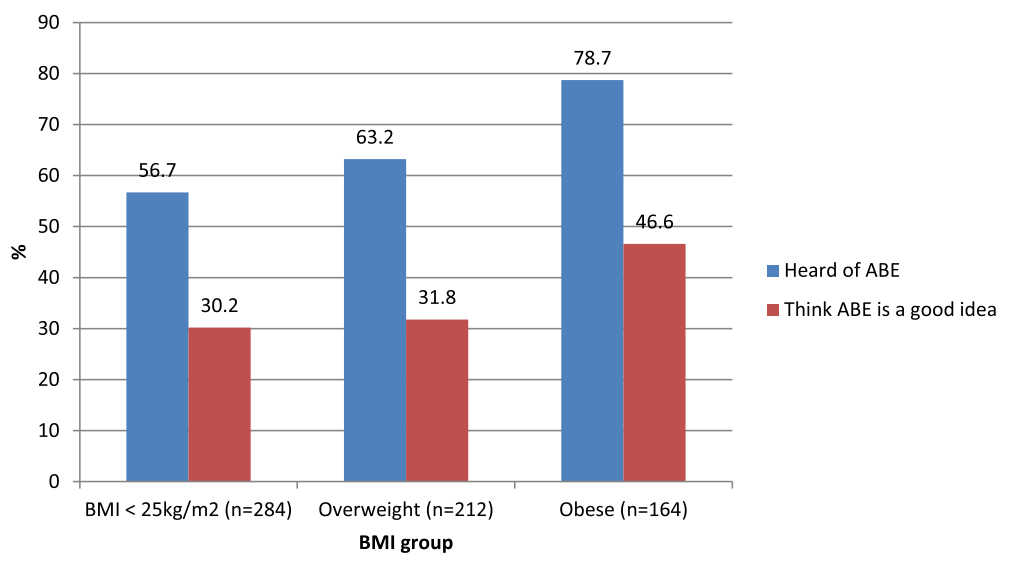

Fig. $3 \mathrm{BMl}$ group and whether participants had heard of $A B E$ and opinion on $A B E$ 
Table 3 Themes from the qualitative data

\begin{tabular}{|c|c|c|}
\hline \multirow[t]{2}{*}{ Participant opinion on ABE } & \multicolumn{2}{|l|}{ Themes from qualitative data } \\
\hline & Second order themes & First order themes \\
\hline \multirow[t]{4}{*}{ It's a good idea } & \multirow[t]{2}{*}{ Beneficial when mother or baby have medical problems } & $\begin{array}{l}\text { Helpful if mother: } \\
\text { has gestational diabetes } \\
\text { has pre-existing diabetes } \\
\text { had breast surgery } \\
\text { has low supply } \\
\text { is unwell } \\
\text { has complications after birth }\end{array}$ \\
\hline & & $\begin{array}{l}\text { Beneficial if baby: } \\
\text { has low blood sugar } \\
\text { has to go to neonatal unit } \\
\text { is premature } \\
\text { has jaundice } \\
\text { has weight loss } \\
\text { has difficulty feeding } \\
\text { has tongue-tie }\end{array}$ \\
\hline & \multirow[t]{2}{*}{ Preparation for successful breastfeeding } & $\begin{array}{l}\text { Gaining confidence with expressing technique } \\
\text { Establishing a supply of milk } \\
\text { Hormone stimulation } \\
\text { Encourage milk production and supply } \\
\text { Avoid the use of formula milk }\end{array}$ \\
\hline & & To promote labour \\
\hline \multirow[t]{2}{*}{ It's not a good idea } & Interfering with nature & $\begin{array}{l}\text { Nature gets it right } \\
\text { Milk extraction should be after birth } \\
\text { Using up the colostrum } \\
\text { No need to interfere }\end{array}$ \\
\hline & Harmful & $\begin{array}{l}\text { May induce early labour or miscarriage } \\
\text { Painful } \\
\text { Stressful } \\
\text { Bullying women to do it }\end{array}$ \\
\hline I'm not sure if it's a good idea & Lack of knowledge & $\begin{array}{l}\text { Never heard of it } \\
\text { Don't know of risks/benefits }\end{array}$ \\
\hline
\end{tabular}

"A good idea to have some milk stored to avoid formula top ups if struggling to feed."

"I would have found it helpful... to have already got used to hand expressing as this was something I needed to do a lot once baby was born."

A few women also reported that $\mathrm{ABE}$ could be beneficial in promoting the onset of spontaneous labour;

"...It is used to induce labour naturally."

\section{Negative perceptions}

Participants who felt that $\mathrm{ABE}$ was a bad idea raised concerns that it would be harmful; causing preterm labour, painful to undertake, stressful, and result from bullying women to do it. They were also concerned that it was interfering with the natural process of initiating breastfeeding;

"I worried it would cause early labour."
"Nature gets this right, no need to interfere."

"Worried of making that [colostrum] go and turn straight into milk when baby arrives."

\section{Uncertain perceptions}

The predominant theme amongst the participants who were unsure if $\mathrm{ABE}$ was a good idea was their lack of knowledge; either that they had not heard of it or did not have enough information about the benefits or risks involved;

\section{"Have never heard of it or its benefits /negatives."}

"I didn't know it could be done."

\section{"I...was never given any information."}

The participants identified a number of factors that would encourage them to express breastmilk in pregnancy (See Table 4). 
Table 4 rFactors that would encourage participants to express breastmilk in pregnancy

Having evidence-based information about ABE

If $A B E$ was found to increase the likelihood of successful breastfeeding and avoiding the use of formula milk

If there were benefits to the baby

Any medical problems prior to the birth, such as diabetes

Knowing that the baby would have medical problems after birth

Reassurance of the safety of doing $A B E$

The support of midwives in the antenatal period

The provision of equipment to undertake $\mathrm{ABE}$

\section{Discussion}

This cross-sectional study has provided insight into women's knowledge and practices surrounding ABE and the acceptability of ABE to mothers. These findings are important as implementation evidence, as this practice is already advised by midwives in many hospitals [30-43], and promoted in some lactation support literature [29, 45].

This survey demonstrated relatively high awareness, with more than half of the participants having heard of $\mathrm{ABE}$. It also found relatively high compliance amongst women who had been advised to do ABE, with $67.9 \%$ of women reporting they had followed this advice. Soltani and Scott [49] found lower compliance, with less than half of women who had been advised to express actually undertaking ABE. It is not clear why $32.1 \%$ of participants who had been advised to do ABE did not follow this advice and this warrants further investigation into the decision making process for undertaking ABE. Furthermore $20.6 \%$ of those who had undertaken $A B E$ were unsure if $\mathrm{ABE}$ was a good idea, and further investigation into women's sources of knowledge about $\mathrm{ABE}$ is needed.

Although a majority of participants $(57.8 \%)$ were unsure if $A B E$ was a good idea, $A B E$ was found to be largely acceptable to the women. A high proportion would consider doing $\mathrm{ABE}$ if it was found to beneficial (79.5\%), including $96.9 \%$ of women who had previously done $\mathrm{ABE}$ and $78.1 \%$ of those who had not previously undertaken $\mathrm{ABE}$. This reflects wider evidence which demonstrated that $95 \%$ of participants who had undertaken $\mathrm{ABE}$ would do it again if it was found to be safe and effective [46].

Participants identified ABE as a form of preparation for breastfeeding and helpful in avoiding the use of formula milk. This reflects other findings that women who undertake $\mathrm{ABE}$ report increased confidence and readiness for breastfeeding, the benefit of learning the technique to use postnatally, and a reduced need for artificial milk supplementation [46].

Concerns raised by participants about the potential of $\mathrm{ABE}$ to cause harm included the pain of the procedure and the risk of causing preterm labour. Forster et al. [46] reported $19.2 \%$ of women undertaking $\mathrm{ABE}$ experienced nipple pain and 26\% experienced Braxton Hicks or contractions, although none attributed ABE to the onset of spontaneous labour. This survey did not enable us to determine if $\mathrm{ABE}$ had any impact on timing of the onset of labour. While a large multi-centred randomised controlled trial of women with diabetes in pregnancy who were at low risk of complications suggested no impact on gestational age at delivery from the practice of $\mathrm{ABE}$ [48], other smaller studies with less stringent eligibility criteria have suggested both a trend towards lower gestational age at delivery and an increased rate of special care baby admissions for babies whose mothers had undertaken $\mathrm{ABE}[46,49]$. Further evidence about the safety of ABE is therefore needed, particularly in pregnant women without diabetes. It is notable that a large proportion (54.3\%) of women in this survey who undertook $\mathrm{ABE}$ commenced $\mathrm{ABE}$ prior to 37 weeks of pregnancy, and it is important to inform women if they decide to undertake $\mathrm{ABE}$ that commencing after 37 weeks of pregnancy will reduce the likelihood of preterm birth [49].

Women of childbearing age in this survey who were in the overweight or obese subgroups were more likely to have heard of $\mathrm{ABE}$ and were more likely to think that $\mathrm{ABE}$ was a good idea, and were no less likely, than women of normal weight, to undertaken it if it was found to be helpful for breastfeeding. This is significant as women in the overweight or obese subgroups typically have higher rates of medical problems such as diabetes $[6,23]$ and lower rates of successful breastfeeding outcomes [6-13]. If the safety and efficacy of ABE is established, they could therefore be considered to be an important target group for this intervention.

\section{Strengths and limitations}

This survey included a large sample of women from a wide spread of UK locations. Comparing UK participants' characteristics with national population data from England, demonstrated that this sample were more predominantly of a white ethnic group and there were a considerably lower proportion of Asian respondents. The sample was also older and of higher socioeconomic status, as indicated by occupation, than the current childbearing population, and hence some of their views and experiences may not be representative. The BMI distribution of the UK participants was very similar to that in the national population.

Undertaking this survey using online technology facilitated wide access and a high response rate that covered wide geographical areas with minimum resources. A maternity user group representative leading survey recruitment may have been an advantage to encourage such a large response rate. However, as a retrospective, self- 
reported questionnaire, it may have been subject to selective recall bias. The sample demonstrated a much higher breastfeeding rate than that of the national childbearing population in England; 98.4\% of the participants reported they had breastfed, compared with the national breastfeeding rate of $74.3 \%$ at birth [52]. The participants had also breastfed for longer with $95.2 \%$ breastfeeding at 8 weeks compared to the national figure for England of 43.8\% [52], and 84.0\% reported breastfeeding at 6 months, compared to $34 \%$ of the national childbearing population [5]. This was therefore a self-selected sample of women who were highly motivated and successful breastfeeding mothers, and may not represent the opinions of the wider population. Nevertheless, even assuming a higher rate of motivation, a large proportion had concerns for implementing $\mathrm{ABE}$ and in depth analysis of their views are worthy of further investigation and consideration.

\section{Conclusion}

Amongst women who have breastfed, many have heard of $\mathrm{ABE}$, and compliance with advice to undertake $\mathrm{ABE}$ is relatively high. $\mathrm{ABE}$ appears to be acceptable to many women, including those in overweight or obese subgroups. However, the benefit and safety of $\mathrm{ABE}$ needs to be established to address the needs of childbearing women for evidence-based information about this practice. If $\mathrm{ABE}$ is demonstrated to be beneficial in the promotion of breastfeeding, overweight and obese pregnant women could be an important target group for this intervention.

\section{Additional file}

Additional file 1: Map showing geographical distribution of UK respondents $(n=688) .($ DOCX $432 \mathrm{~kb})$

\section{Abbreviations}

ABE: Antenatal breast expression; BMI: Body mass index; IQR: Interquartile range; NS-SEC: National Statistics Socio-economic Classification;

PPH: Postpartum haemorrhage; SD: Standard deviation; UK: United Kingdom

\footnotetext{
Acknowledgements

First of all, we would like to thank all the women who completed the online survey. We thank South Yorkshire Collaboration for Leadership in Applied Health Research and Care (CLAHRC-SY) for funding Helen Watson's involvement in the project, and Jo Cooke for facilitating this involvement. NIHR CLAHRC for South Yorkshire acknowledges funding from the Health Education England (HEE). The views and opinions expressed are those of the authors, and not necessarily those of the NHS, HEE, or the Department of Health. Further details can be found at http://clahrc-sy.nihr.ac.uk/. We would also like to thank Karen Kilner for her advice on the statistical analysis undertaken in this work
}

\section{Funding}

No external funding was allocated to this project.
Availability of data and materials

The datasets analysed during the current study are available from the corresponding author on reasonable request.

\section{Authors' contributions}

FF - study conception and survey design, cleaned and analysed the data, revised the manuscript, approved the final manuscript. HW - cleaned and analysed the data, prepared the initial manuscript draft, approved the final manuscript. RG - study conception and survey design, maternity user group liaison, lead survey distribution and promotion, approved the final manuscript. HS - study conception and survey design, revised the manuscript, approved the final manuscript.

\section{Ethics approval and consent to participate}

Ethical approval was obtained from Sheffield Hallam University Research Ethics Committee, study ID: 2015-16/ HWB-HSC-14.Consent was assumed inherent for the participants who completed the questionnaire voluntarily.

\section{Consent for publication}

Not applicable

Competing interests

The authors declare that they have no competing interests.

\section{Publisher's Note}

Springer Nature remains neutral with regard to jurisdictional claims in published maps and institutional affiliations.

\section{Author details}

${ }^{1}$ Faculty of Health and Wellbeing, Sheffield Hallam University, Collegiate Crescent, Sheffield, UK. ${ }^{2}$ Sheffield Maternity Services Liaison Committee and Sheffield user group charity - Forging Families, Sheffield, UK.

Received: 26 June 2017 Accepted: 19 March 2018

Published online: 04 April 2018

\section{References}

1. WHO. The optimal duration of exclusive breastfeeding. Report of the expert consultation. Geneva: WHO; 2001. http://apps.who.int/iris/bitstream/10665/ 67219/1/WHO_NHD_01.09.pdf?ua=1. Accessed 10 Sept 2016

2. Eidelman Al, Schanler RJ, Johnston $M$, et al. Breastfeeding and the use of human milk. American Academy of Pediatrics policy statement. Pediatrics. 2012;129:e827-41.

3. Salone LR, Vann WF Jr, Dee DL. Breastfeeding. An overview of oral and general health benefits. J Am Dent Assoc. 2013;144(2):143-51. https://doi. org/10.14219/jada.archive.2013.0093.

4. Lessen R, Kavanagh K. Position of the academy of nutrition and dietetics: promoting and supporting breastfeeding. J Acad Nutr Diet. 2015; https:// doi.org/10.1016/j.jand.2014.12.014.

5. McAndrew F, et al. (2012) infant feeding survey 2010. Leeds: Health and Social Care Information Centre; 2012. http://content.digital.nhs.uk/ catalogue/PUB08694/Infant-Feeding-Survey-2010-Consolidated-Report.pdf. Accessed 1 Oct 2016

6. Amir LH, Donath S. A systematic review of maternal obesity and breastfeeding intention, initiation and duration. BMC Pregnancy Childbirth. 2007; https://doi.org/10.1186/1471-2393-7-9.

7. Mok E, Multon C, Piguel L, Barroso E, Goua V, Christin P, et al. Decreased full breastfeeding, altered practices, perceptions, and infant weight change of prepregnant obese women: a need for extra support. Pediatrics. 2008; https://doi.org/10.1542/peds.2007-2747.

8. Krause KM, Lovelady CA, Østbye T. Predictors of breastfeeding in overweight and obese women: data from active mothers postpartum (AMP). Mater Child Health J. 2011; https://doi.org/10.1007/s10995-010-0667-7.

9. Lepe M, Bacardí Gascón M, Castañeda-González LM, Pérez Morales ME, Jiménez CA. Effect of maternal obesity on lactation: systematic review. Nutr Hosp. 2011; https://doi.org/10.1590/S0212-16112011000600012.

10. Wojcicki JM. Maternal prepregnancy body mass index and initiation and duration of breastfeeding: a review of the literature. J Women's Health. 2011; https://doi.org/10.1089/jwh.2010.2248. 
11. Thompson LA, Zhang S, Black E, Das R, Ryngaert M, Sullivan S, et al. The association of maternal pre-pregnancy body mass index with breastfeeding initiation. Mater Child Health J. 2013; https://doi.org/10.1007/s10995-012-1204-7.

12. Hauff $L E$, Leonard $S A$, Rasmussen KM. Associations of maternal obesity and psychosocial factors with breastfeeding intention, initiation, and duration. Am J Clin Nutr. 2014; https://doi.org/10.3945/ajcn.113.071191.

13. Babendure JB, Reifsnider E, Mendias E, Moramarco MW, Davila YR. Reduced breastfeeding rates among obese mothers: a review of contributing factors, clinical considerations and future directions. Int Breastfeed J. 2015; https:// doi.org/10.1186/s13006-015-0046-5.

14. Turcksin $\mathrm{R}$, et al. Maternal obesity and breastfeeding intention, initiation, intensity and duration: a systematic review. Mater Child Nutr. 2014; https:// doi.org/10.1111/j.1740-8709.2012.00439.

15. Stevens $\mathrm{G}$, et al. National, regional, and global trends in adult overweight and obesity prevalences. Popul Health Metrics. 2012; https://doi.org/10. 1186/1478-7954-10-22

16. $\mathrm{Ng} \mathrm{M}$, et al. Global, regional, and national prevalence of overweight and obesity in children and adults during 1980-2013: a systematic analysis for the global burden of disease study 2013. Lancet. 2014; https://doi.org/10. 1016/S0140-6736(14)60460-8.

17. Guelinckx I, Devlieger R, Bogaerts A, Pauwels S, Vansant G. The effect of prepregnancy BMI on intention, initiation and duration of breast-feeding. Public Health Nutr. 2012; https://doi.org/10.1017/S1368980011002667.

18. Leonard SA, Labiner-Wolfe J, Geraghty SR, Rasmussen KM. Associations between high prepregnancy body mass index,breast-milk expression, and breast-milk production and feeding. Am J Clin Nutr. 2011; https://doi.org/10. 3945/ajcn.110.002352.

19. Chapman DJ, Perez-Escamilla R. Maternal perception of the onset of lactation is a valid, public health indicator of lactogenesis stage II. J Nutr. 2000;130:2972-80.

20. Neville MC, Morton J. Physiology and endocrine changes underlying human lactogenesis II. J Nutr. 2001;131:3005S-8S.

21. Hartmann P, Cregan M. Lactogenesis and the effects of insulin-dependent diabetes mellitus and prematurity. J Nutr. 2001;131:3016S-20S.

22. Hilson JA, Rasmussen KM, Kjolhede CL. High prepregnant body mass index is associated with poor lactation outcomes among white, rural women independent of psychosocial and demographic correlates. J Hum Lact. 2004; https://doi.org/10.1177/0890334403261345.

23. Marchi J, Berg M, Dencker A, Olander EK, Begley C. Risks associated with obesity in pregnancy, for the mother and baby: a systematic review of reviews. Obes Rev. 2015;16:621-38.

24. Rasmussen KM, Kjolhede CL. Prepregnant overweight and obesity diminish the prolactin response to suckling in the first week postpartum. Pediatrics. 2004;113:e465-71.

25. Singh G, Chouban R, Sidhu K. Effect of antenatal expression of breastmilk at term in reducing breastfeeding failures. Med J Armed Forces of India. 2009; https://doi.org/10.1016/S0377-1237(09)80125-1

26. West $D$, Marasco L. Getting your milk supply off to a good start. The breastfeeding mother's guide to making more milk. New York: McGraw-Hill; 2009

27. East CE, Dolan WJ, Forster DA. Antenatal breast milk expression by women with diabetes for improving infant outcomes. Cochrane Database Syst Rev. 2014;7:CD010408.

28. Cox SG. Expressing and storing colostrum antenatally for use in the newborn period. Breastfeed Rev. 2006;143:11-6.

29. Britain LLLG. Antenatal expression of colostrum. Information sheet no. 2811. Nottingham, Great Britain: LaLeche League Great Britain; 2010.

30. Blackpool Teaching Hospitals NHS Foundation Trust. Antenatal Banking of Colostrum. 2012. http://www.bfwh.nhs.uk/wp-content/uploads/2015/08/ PL716.pdf. Accessed 31 May 2017.

31. Buckinghamshire Healthcare NHS Trust. Antenatal hand expression. 2016. http:// www.buckshealthcare.nhs.uk/Downloads/Patient-leaflets-pregnancy-labour-andpostnatal-care/Antenatal\%20hand\%20expression.pdf. Accessed 31 May 2017.

32. Dartford and Gravesham NHS Trust. Expressing your breastmilk in pregnancy. 2014. http://www.google.co.uk/url?sa=t\&rct=j\&q=\&esrc= s\&source $=$ web\&cd $=10 \& c a d=$ rja\&uact $=8 \&$ ved $=$ OahUKEwjxrLnep5rUAhWpJsAKHW__BdcQFghiMAk\&url= http\%3A\%2F\%2Fwww.dvh.nhs.uk\%2FEasySiteWeb\%2FGatewayLink. aspx\%3Falld\%3D165903\&usg=AFQjCNFc0ofNv5-rbnURq2RJmYxgQ_eL9g Accessed 31 May 2017.

33. Derby Teaching Hospital NHS Foundation Trust. Antenatal hand expression of colostrum, draft guideline. Derby: Derby Hosital; 2007.
34. Guys and St Thomas' NHS Foundation Trust. Information about antenatal hand expressing from 37 weeks. 2016. http://www.guysandstthomas.nhs.uk/ resources/patient-information/maternity/antenatal-hand-expressing-from-37weeks.pdf. Accessed 31 May 2017.

35. Kettering General Hospital NHS Foundation Trust. Women and Child Health. Antenatal Hand Expressing. Patient information. 2015. Leaflet http:// webcache.googleusercontent.com/search?q=cache:twalAGhsJKOJ:www.kgh. nhs.uk/EasysiteWeb/getresource.

axd\%3FAssetID\%3D12848\%26type\%3Dfull\%26servicetype\%3DAttachment $+\& c d=1 \& h|=e n \& c t=c| n k \& g l=u k$. Accessed 31 May 2017.

36. Lancashire Teaching Hospitals. NHS Foundation Trust. Expressing your Milk Antenatally. 2015. https://www.lancsteachinghospitals.nhs.uk/download. cfm?doc=docm93jijm4n3852. Accessed 31 May 2017.

37. Royal Berkshire NHS Foundation Trust. Expressing colostrum in pregnancy 2016. http://www.royalberkshire.nhs.uk/patient-information-leaflets/ maternity_expressing-colostrum.htm. Accessed 31 May 2017.

38. Royal Cornwall Hospitals. Antental hand expressing of breastmilk for type 1 , type 2 or gestational diabetes. Clinical Guideline. 2016. http://www.rcht.nhs. uk/DocumentsLibrary/RoyalCornwallHospitalsTrust/Clinical/ MidwiferyAndObstetrics/BreastmilkGuidelinesForAntenatalHandExpressingOf. pdf Accessed 31 May 2017

39. Royal Surrey County Hospital NHS Foundation Trust. Expressing your breastmilk in pregnancy. 2014. http://www.royalsurrey.nhs.uk/wp-content/ uploads/2015/09/PIN072_Expressing_your_breast_milk_in_pregnancy_W. pdf. Accessed 31 May 2017.

40. Sandwell and West Birmingham NHS Trust. Expressing your milk antenatally. 2014. http://www.swbh.nhs.uk/wp-content/uploads/2012/06/Expressingyour-milk-antenatally-ML4692.pdf. Accessed 31 May 2017.

41. South Devon Healthcare NHS Foundation Trust. Breatsfeeding information for women. 2015. http://www.torbayandsouthdevon.nhs.uk/uploads/25120. pdf Accessed 31 May 2017.

42. Southend University Hospital NHS Foundation Trust. Antenatal expressing and storage of your colostrum. 2015. http://www.southend.nhs.uk/media/ 180174/antenatal_expressing_and_storage_of_your_colostrum_sou4353 037980_0715_v1_web.pdf. Accessed 31 May 2017.

43. Wrightington, Wigan and Leigh NHS Foundation Trust. Colostrum harvesting/expressing your milk in the antenatal period. 2017. https:/www. wwl.nhs.uk/Library/All_New_PI_Docs/Audio_Leaflets/Obstetrics/colostrum/ obs050_colostrum_harvesting619v3.pdf. Accessed 31 May 2017.

44. Pathak S. Practice of antenatal breast expression in National Health Service in England. Int J Health Res Medico Legal Pract. 2017;3:12-4.

45. Association of Breastfeeding Mothers. Expressing your milk before your baby arrives: antenatal expression of colostrum. 2017. https:/abm.me.uk/expressingmilk-baby-arrives-antenatal-expression-colostrum/. Accessed 31 May 2017.

46. Forster DA, McEgan K, Ford R, Moorhead A, Opie G, Walker S, et al. Diabetes and antenatal milk expressing: a pilot project to inform the development of a randomised controlled trial. Midwifery. 2011;27:209-14.

47. Chapman T, Pincombe J, Harris N. Antenatal breast expression: a critical review of the literature. Midwifery. 2013; https://doi.org/10.1016/.midw. 2011.12.013

48. Forster DA, Moorhead AM, Jacobs SE, et al. Advising women with diabetes in pregnancy to express breastmilk in late pregnancy (diabetes and antenatal milk expressing [DAME]): a multicentre, unblinded, randomised controlled trial. Lancet. 2017;389:2204-13.

49. Soltani $\mathrm{H}$, Scott AMS. Antenatal breast expression in women with diabetes: outcomes from a retrospective cohort study. Int Breastfeed J. 2012; https:// doi.org/10.1186/1746-4358-7-18.

50. WHO. BMI Classification. 2016. http://apps.who.int/bmi/index.jsp?introPage= intro_3.html. Accessed 8 July 2016.

51. ONS. Volume 3 The National Statistics Socio-economic Classification: (Rebased on the SOC2010) User Manual. 2010. http://webarchive. nationalarchives.gov.uk/20160105160709/http://www.ons.gov.uk/ons/ guide-method/classifications/current-standard-classifications/soc2010/ soc2010-volume-3-ns-sec\%2D-rebased-on-soc2010\%2D-user-manual/ index.html. Accessed 8 July 2016.

52. NHS England. NHS England statistical release breastfeeding initiation and breastfeeding prevalence 6-8 weeks. 2015. https://www.england.nhs.uk/ statistics/wp-content/uploads/sites/2/2014/03/Breastfeeding-1516Q11.pdf. Accessed 29 Sept 2016.

53. HSCIC. Hospital Episode Statistics. NHS Maternity Statistics - England, $2012-$ 13. 2015. https://digital.nhs.uk/catalogue/PUB12744. Accessed 1 Oct 2016. 
54. HSCIC. NHS Maternity Statistics England 2013-14 2015 http://digital.nhs.uk/ catalogue/PUB16725. Accessed 3 Oct 2016.

55. HSCIC. Statistics on obesity, physical activity and diet England. 2015. http:// content.digital.nhs.uk/catalogue/pub16988/obes-phys-acti-diet-eng-2015.pdf. Accessed 3 Oct 2016.

56. ONS. 2011 Census: Key Statistics and Quick Statistics for Local Authorities in the United Kingdom. 2011. http://www.ons.gov.uk/employmentandlabourmarket/ peopleinwork/employmentandemployeetypes/bulletins/

keystatisticsandquickstatisticsforlocalauthoritiesintheunitedkingdom/2013-1204\#national-statistics-socio-economic-classification-ns-sec. Accessed 23 Nov 2016.

Submit your next manuscript to BioMed Central and we will help you at every step:

- We accept pre-submission inquiries

- Our selector tool helps you to find the most relevant journal

- We provide round the clock customer support

- Convenient online submission

- Thorough peer review

- Inclusion in PubMed and all major indexing services

- Maximum visibility for your research

Submit your manuscript at www.biomedcentral.com/submit 